\title{
LA PRESENCIA DE DIEGO RIVERA EN LOS ESTADOS UNIDOS: DOS VERSIONES DE LA HISTORIA
}

Alicia AzUELA

Con este breve ensayo intitulado "La presencia de Diego Rivera en Los Estados Unidos: dos Versiones de la Historia" deseo presentar la metodología y el producto de la investigación que utilicé para la elaboración del libro Diego Rivera en Detroit. ${ }^{1}$ Persigo ilustrar un problema compartido con frecuencia por los historiadores latinoamericanos; se refiere a las consecuencias que trae consigo la falta de información sobre la obra realizada por artistas coterráneos que trabajan e influyen en el extranjero, limitación que repercute sobre la posibilidad de evaluar en su totalidad la vida y la obra del artista y oscurece una parte vital de la propia historia del artista, que es la que se refiere a su repercusión fuera de las propias fronteras.

En este ejemplo aparece también el agravante de que se influyó sobre un país al que no le interesaba analizar y reconocer esa influencia, porque la había englobado dentro de una etapa de su propia historia, que en términos artísticos aún hoy considera inferior y a niveles políticos censurable.

Fue esta versión de los hechos la que llegó a predominar también en la nación que generó la influencia por darse con ella una relación de dependencia económica, política y cultural.

El caso de Diego Rivera es por demás aleccionador en este sentido. Su persona forma parte de la mitología nacional mexicana. A más de cincuenta años de su muerte aún despiertan fuertes polémicas sus usuales contradicciones ideológicas y la admiración por su obra se generaliza y extiende más allá de nuestras fronteras.

Esta postura compartida por el público y sostenida por los historiadores nacionales resulta contrastante con la poca o nula importancia que se le daba hace poco al artista en historias del arte escritas fuera de México.

1 Azuela, Alicia, Diego Rivera en Detroit, México, Universidad Nacional Autónoma de México, 1983. 
El caso resultaba especialmente notable hace apenas diez años, antes de que Ramón Favela y el Detroit Institute of Arts revaloraran su obra y la difundieran a nivel internacional.

Cuando se pretendía buscar información sobre la labor artística de Rivera en los Estados Unidos, dentro de la literatura que sobre el tema existía en la propia Historia del Arte Moderno Estadounidense; tanto el periodo artístico en que había tenido lugar los hechos, como la obra que allí había realizado, se juzgaban con desdén.

En México se conocía ampliamente su trayectoria dentro del país pero poco se decía de su actividad artística en el extranjero. La obra más conocida era la destruida por los Rockefeller en el Radio City de Nueva York, debido al conflicto en sí que suscitó y la posterior reproducción de los frescos en el Palacio de Bellas Artes en México.

Su biógrafo Bertman D'Wolfe en La fabulosa vida de Diego Rivera ${ }^{2}$ daba una amplia información, pero por demás apasionada. Otros autores, como Jean Charlot ${ }^{3}$ o Bernard Myers, ${ }^{4}$ se referían a ese periodo de la vida del artista. Lo hacían, sin embargo, brevemente y siempre con la carga emotiva que deja ser juez y parte.

Todos ellos proporcionaban una serie de datos por demás llamativos, si se pensaba en relación a la obra e ideología del artista y sobre todo la manera en que se juzgaba o ignora su labor, en la literatura sobre arte estadounidense, a partir de los años cincuenta.

Entre 1929 y 1935 el artista había pintado siete murales en los Estados Unidos y sólo uno de ellos había sido para un grupo de izquierda: el de los lovestonianos, grupo troskista que ofreció la sede de la New Workers School para que el artista ilustrara la historia del movimiento obrero estadounidense. El resto de las obras las habían patrocinado personajes del mundo financiero e industrial de este país entre los que se encontraban las familias Ford y Rockefeller, la Bolsa de Valores de San Francisco y el Museo de Arte Moderno de Nueva York.

A Rivera por otro lado se le conocía por sus ligas permanentes con distintas facciones de la izquierda y la consecuente actitud anti-imperialista que en todos ellos compartía. Su obra aunque era poco conocida en México, de lo que se podía ver se deducía un gran valor artístico. El propio Rivera había afirmado en múltiples ocasiones su

2 D'Wolfe, Bertram, La fabulosa vida de Diego Rivera, México, Diana, 1972.

3 Charlot, Jean, "An artist on art", Collected Essays of Jean Chartot, Honolulu, University Press of Hawaii, 1972.

4 Myers, Bernard, Mexican Painting in own time, Nueva York, Oxford University Press, 1956. 
predilección por los murales que en la década de los treintas pintó en los Estados Unidos a tal grado que junto con sus frescos de Chapingo sentía que "el homenaje a Detroit" del Detroit Institute of Art eran los que mayor calidad artística poseían.

Dentro de la historia general del arte mexicano, esta información no se manejaba bajo la perspectiva de una posible repercusión de nuestra propia historia en el exterior.

Existían muy pocos datos en México al respecto, porque en el momento en que se dio ese fenómeno no se alcanzó a percibir el peso de su repercusión.

Más tarde nuestra propia evolución artística la oscureció llegando a predominar en un amplio sector, muchos de los argumentos que componían la interpretación que desde fuera daban sobre ella.

Una parte importante de los historiadores del arte estadounidense tendieron, a partir de la década de los cincuenta, a contraponer el valor del Expresionismo Abstracto, surgido en la década de los cincuenta, a la serie de obras que con un tono realista y una finalidad social se hicieron de finales de 1920 a mediados de 1940 , periodo en el que el arte y la cultura mexicana tuvieron un fuerte impacto sobre los Estados Unidos.

Esa tendencia historiográfica tuvo una creciente importancia en nuestro pais, porque ayudó a fortalecer cambios determinantes en el arte mexicano.

Esta transformación se da con el enfrentamiento de la joven generación con la denominada Escuela Mexicana de Pintura que a través de algunos de sus miembros, entre los que estaba Diego Rivera, habían convertido la que fuera la más importante manifestación artística contemporánea mexicana, en una anquilosada tradición que impedía el surgimiento de nuevas maneras de hacer arte.

Entre los artistas jóvenes fue precisamente el Expresionismo Abstracto uno de los movimientos que mayor influencia ejercieron sobre ellos. Con muchos de los argumentos que en Estados Unidos utilizaron para menospreciar el arte de los treinta, ellos mismos atacaron a la Escuela Mexicana de Pintura que por un buen tiempo también cayó en el desprestigio.

En el proceso de investigación para elaborar el libro Diego Rivera en Detroit, esta visión del arte de los Estados Unidos, que tan bien estudian autores como Shifra Golmann, junto con la falta de información y contradicciones que habian en la historia del arte mexicano, determinaron la necesidad de recurrir a fuentes primarias, que permitieron 
rehacer no sólo esta etapa de la vida de Rivera, sino también del contexto artístico estadounidense en que tuvo lugar.

El punto de partida para la incursión en ellas lo proporcionaron los libros básicos de la época ya citados aquí: La fabulosa vida de Diego Rivera, The Mexican Mural Renassance ${ }^{5}$ y otros más. Estos aportaron además de una panorámica general de los hechos, una rica hemerografía que abrió la puerta más importante para la realización de este estudio.

Se trataba en su mayoría de artículos de esa época provenientes de revistas de arte, además de otras que como The New Masses, o The Workers Eage, contenían riquísimas secciones de arte elaboradas por artistas y críticos de izquierda.

La riqueza del material era enorme, además de remitir a numerosos artículos no citados en la biliografía básica, al leerse dentro del contexto en que se escribieron era posible tener una visión muy amplia de los hechos.

Los escritos que en su mayoría eran polémicos, denotaban antagonismos importantes entre distintos grupos y hacían referencias constantes a acontecimientos históricos del momento, indefectiblemente ligados a la crisis del 29.

Estas características de las fuentes determinaron que para tener una visión cabal de los hechos fuera necesario estudiar el periodo artístico en que tuvieron lugar, y de éste en su relación con el contexto general de la historia de Estados Unidos.

El número enorme de artículos que se encontraron, por sí mismo mostraba el interés en la presencia de Diego Rivera y hacía todavía más dudoso el hecho de que no hubiera dejado ninguna influencia en el medio artístico de la época.

En la prensa no sólo se hablaba de él, con igual pasión se escribía sobre Orozco y Siqueiros o se hacían referencias a un sinnúmero de actividades artísticas mexicanas que tenían lugar en Estados Unidos o México.

Otra peculiaridad de las publicaciones era que con frecuencia habían sido escritos por personajes de gran importancia dentro de la cultura de ambos países. En este foro cabía la opinión de intelectuales de diversas tendencias ideológicas que se interesaban por muchos otros campos de la cultura. Factor que también abrió las puertas para descubrir un fenómeno aún más ignorado y contundente: el de la importan-

5 Charlot, Jean, The Mexican Mural Renassance, 1920-1925, New Haven, Yale University Press, 1963. 
cia de la presencia e impacto de los intelectuales y artistas mexicanos en los Estados Unidos, con la correspondiente rica y estrecha relación que entonces se dio entre ambos países a través de la cultura.

Los resultados obtenidos después de seguir ese proceso de investigación fueron vitales para comprender el alcance que tuvo en la vida y la obra de Rivera, su estancia en los Estados Unidos. También nos proporcionó las herramientas para conocer el enorme peso que tuvo su presencia sobre el arte estadounidense de esa época.

Dentro de la carrera artística de Rivera fue éste un momento determinante. Entraron más que nunca en conflicto su vocación artística con sus creencias políticas. Venciendo la primera sobre la segunda.

Por ello, el significado que dentro de su trayectoria de militante de izquierda pudo haber tenido el pintar Detroit, bajo el mecenazgo de grandes capitalistas como la familia Ford o la Rockefeller ocupó un segundo lugar frente a la posibilidad de pintar en el corazón de la industria.

Como todo artista de vanguardia tenía una especial fascinación por la belleza de la máquina. Su antiguo interés por la ciencia y la tecnología volvía fascinante la opción de estudiar y retratar los procesos fabriles de producción. Esta oportunidad le permitía además poner en práctica las ideas que por muchos años había elaborado sobre el arte proletario y enriquecerlas con las experiencias que pudo obtener, al hacer arte público en México con su pintura mural.

La obra que dejó en los Estados Unidos nació de la conjunción de todos estos intereses que fructificaron en siete murales elaborados entre los años de 1929 a 1936. Entre todos ellos el fresco "Homenaje a la industria de Detroit" 1932-1933 que pintó para el Instituto de Artes de Detroit es sin lugar a duda uno de sus mejores murales y posiblemente el tributo más importante y más bello que en términos artísticos se ha hecho en este siglo al mundo fabril.

Además de haber dejado en los Estados Unidos esta serie de fres$\cos$, Rivera ejerció una influencia importante en la producción y el pensamiento artístico estadounidense de esos años. Sobre todo en su búsqueda por elaborar una forma de arte público, capaz de integrar a su lenguaje plástico, los elementos del arte contemporáneo más avanzados; sin perder por ello su capacidad de transmitir con sencillez y calidad grandes mensajes.

Esta investigación al mismo tiempo que permitió esclarecer esa etapa de la vida de Diego Rivera, abrió la posibilidad de conocer uno de los periodos más dignos y enriquecedores de la historia de ese país, 
que se caracterizó, por su liberalidad y apertura hacia maneras de ser y de pensar distintas a las suyas, y la consecuente posibilidad de establecer una enriquecedora relación entre las distintas partes. El conocimiento de ese periodo histórico permitió también entender el porqué de las fuertes reacciones en su contra.

El gobierno estadounidense a partir de mediados de los cuarenta entró en un largo periodo de conservadurismo. Había superado la crisis económica y su positiva intervención en la Segunda Guerra Mundial lo convertía en una gran potencia. Redefine bajo estas circunstancias la manera de ejercer su poderío económico y control político. Toma entonces una actitud imperialista sumamente agresiva que rechaza toda forma distinta a la propia calificándola de comunista. Entonces nace el macartismo, y la cruenta persecución que en ese país se ejerció sobre artistas e intelectuales que pudieron de alguna manera con su vida pasada y presente, resultar sospechosos.

De ahí su reacción en contra del periodo histórico inmediatamente anterior en todas sus manifestaciones y características. La producción artística de esos años es en gran parte por esos mismos motivos menospreciada, independientemente de su calidad estética o de que hubiera sido creada por artistas nacionales o extranjeros.

Frente a estos hechos la posibilidad de haber rescatado una parte tan importante de la vida artística de Diego Rivera y por consecuencia de nuestro país, adquirió nuevas dimensiones.

Significó la posiblidad de separar y entender en su independencia e interrelación con los Estados Unidos, un capítulo de nuestra historia, devaluado entre otros motivos por factores ajenos a sus cualidades intrínsecas y a su trascendencia.

Demostró por consecuencia la importancia que tiene conocer el origen de la interpretación que desde fuera se le da a nuestra historia y la trascendencia que por ello adquiere el que seamos los descubridores de nuestro devenir histórico. 